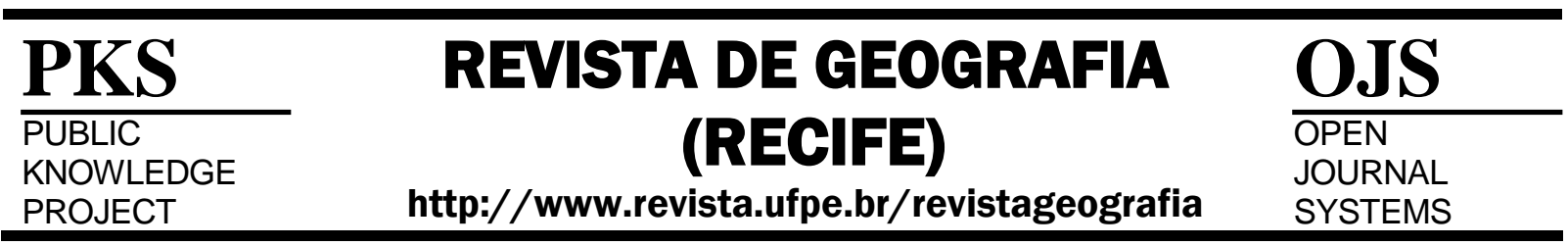

\section{USO DAS IMAGENS SAR R99B PARA MAPEAMENTO GEOMORFOLÓGICO DO CANAL DO ARIAÚ NO MUNICÍPIO DE IRANDUBA-AM}

\author{
Willer Hermeto Almeida Pinto ${ }^{1}$; Ailton Luchiari ${ }^{2}$
}

\author{
${ }^{1}$ Doutor em Geografia Física, USP; Email: willer.hermeto@usp.br \\ ${ }^{2}$ Docente da Universidade de São Paulo; Email: aluchiar@usp.br
}

Artigo recebido em 24/05/2016 e aceito em 15/03/2017

\begin{abstract}
RESUMO
O estudo das formas do relevo terrestre teve um avanço expressivo com a utilização das modernas ferramentas de sensoriamento remoto. Na região Amazônica, devido à vasta cobertura de nuvens, bruma e fumaça, quase que o ano inteiro, de certa forma, ocasiona dificuldade para levantamento com sensores ópticos. As melhores imagens para a região, portanto, são as imagens provenientes de radar, pois esse sistema tem a vantagem de adquirir imagens, independente, da presença de nuvens ou fumaça. Desta forma, este trabalho teve por objetivo principal o uso das imagens do Radar de Abertura Sintética R99B para o mapeamento geomorfológico ao longo do furo do Ariaú no município de Iranduba. A metodologia empregada neste trabalho foi baseada na adaptação dos métodos propostos por Lima (1995), composta de três fases: identificação, análise e interpretação. O método proposto permitiu a interpretação das feições geomorfológicas baseadas na textura das imagens SAR/R99B com múltiplas polarizações para as terras baixas com altitude não ultrapassando $100 \mathrm{~m}$. Como resultado desta pesquisa, obteve-se mapa da drenagem, mapa geomorfológico das feições fluviais na calha do Ariaú. As imagens do SAR mostraram-se eficientes para as diferentes feições geomorfológicas para o mapeamento de média escala nas áreas baixas da Amazônia.
\end{abstract}

Palavras-Chave: Iranduba, imagens SAR, Furo do Ariaú.

\section{THE LINKS BETWEEN THE LOWER CIRCUIT OF THE URBAN ECONOMY IN BOM JESUS DA LAPA AND SPATIAL PRODUCTIVE CIRCUIT OF CLOTHING}

\begin{abstract}
The study of the forms of terrestrial landscape had a significant progress with the use of modern remote sensing tools. In the Amazon region, due to extensive cloud cover, haze and smoke, almost the entire year, somehow, causes difficulty imaging with optical sensors. The best images for the region, are the pictures from Radar because this system has the advantage of acquiring images, independent of the presence of clouds or smoke. Thus, this work aimed to use pictures of the Synthetic Aperture Radar R99B for geomorphological mapping along the "Furo do Ariaú" in the municipality of Iranduba. The methodology used in this study was based on the adaptation of the methods proposed by Lima (1995), composed of three phases: identification, analysis and interpretation. The proposed method allowed the interpretation of geomorphological features based on texture of SAR/R99B images with multiple polarizations to the lowlands to an altitude not exceeding 100m. As a result of this research a map was obtained, including the drainage map, geomorphological map of the river channel Ariaú. The SAR images were effective for different geomorphological mapping to medium scale of low-lying areas of the Amazon.
\end{abstract}

Keywords: Iranduba, SAR images, Furo Ariaú. 


\section{INTRODUÇÃO}

Na bacia amazônica, a forte amplitude de variação do nível d'água do curso hidrológico gera inundações regulares de vastas zonas, denominadas localmente de várzeas. Essas planícies fluviais, ao longo dos grandes rios, induzem à geração de um complexo sistema de canais, lagos, ilhas e diques marginais (SIOLI, 1951; SIOLI, 1984; LATRUBESSE, 2007). Utilizando dados do projeto RADAMBRASIL, Junk (1997), estimou a área inundada na porção central da bacia amazônica a um milhão de $\mathrm{km}^{2}$, sendo que essas áreas se encontram, principalmente, nas margens dos grandes rios dessa região.

Conforme Teixeira et al., (2007), os principais afluentes da margem direita do rio Solimões e o rio Japurá, na margem esquerda, transportam uma elevada carga de sedimentos em suspensão na água. A colmatação desses sedimentos nas planícies de inundação dá origem a solos com estratificação horizontal e vertical (Neossolos Flúvicos) e com características acentuadas de hidromorfismo (Gleissolos). Por sua natureza sedimentar recente, esses solos guardam estreita relação com o material de origem, ou seja, sedimentos provenientes das regiões andinas e subandina, que são transportados pelos rios que drenam a região e depositados na planície aluvial (IRION, 1984) e também sedimentos das formações geológicas de terra firme (HORBE et al., 2007).

Ao longo das últimas décadas, junto com o avanço computacional, o sensoriamento remoto passou a ter uma importância significativa para os estudos ambientais, principalmente nas questões envolvendo a geomorfologia, pois a identificação, o entendimento e a avaliação quanto à natureza das formas de relevo em imagens de sensores remoto é um dos grandes benefícios trazidos pelo uso dessa ferramenta (JENSEN, 1949). Esses avanços têm sido de grande importância para estudos como mapeamentos geomorfológicos, sistemas lacustres e ecologia da paisagem, Almeida Filho e Miranda (2007); Florenzano (2008); Hess et al. (2003); Melack e Hess (2010); Novo et al. (2005); Souza Filho et al. (2006); Teixeira e Sano (2007); entre outros.

Segundo Paradella et al. (2005), na região Amazônica a presença de nuvens, brumas e fumaças impõe restrições ao uso de sensores ópticos. Dessa forma, os dados de radar passam a ter uma importância fundamental, pois, têm a capacidade de prover imagens de elevada resolução espacial, de modo independente de condições atmosféricas e fonte solar. Tudo isso tem uma contribuição significativa para a descrição da forma do relevo desse ambiente. 
Os trabalhos desenvolvidos, utilizando dados de sensoriamento remoto para mapeamento geomorfológico em escala de detalhes, na Amazônia, em relação às terras baixas, são poucos. Apesar do Sistema de Proteção da Amazônia (SIPAM) disponibilizar imagens do Synthetic Aperture Radar (SAR) R99B para a comunidade acadêmica, poucos trabalhos relacionados à geomorfologia têm sido desenvolvidos utilizando esses dados. Segundo Cunha et al. (2003), a cartografia geomorfológica é um dos mais importantes veículos de comunicação e análise dos resultados obtidos sobre as formas do relevo e dos processos que atuam em determinado local.

O principal estudo sobre o relevo da Amazônia se deu na década de 1970 com o projeto RADAMBRASIL. No entanto, apesar da grande contribuição desse projeto, o mapeamento foi realizado em pequena escala, ocasionando uma lacuna para o entendimento do relevo local, onde a pouca cobertura cartográfica sistemática, em escala de detalhamento, ocasiona dificuldade no entendimento das formas predominantes de relevo.

Desta forma, esta pesquisa teve como objetivo a identificação das formas de relevo existentes na área do furo do Ariaú, utilizando as imagens do SAR/R99B para o mapeamento geomorfológico.

\section{Caracterização da área}

A área de estudo situa-se na região da Bacia do Amazonas, entre os municípios de Iranduba e Manacapuru nos seguintes paralelos $3^{\circ} 00^{\prime} 00^{\prime \prime} \mathrm{S}$ e $3^{\circ} 20^{\prime} 00^{\prime}$ ' S e meridianos $60^{\circ}$ 20’00” W e 60³0'00” W. Essa área recobre parte das folhas SA-20-Z-D-III-1 Lago do Limão e SA-20-Z-D-III-3 Colônia Boa Vista (Figura 1).

O furo do Ariaú liga dois dos maiores sistemas fluviais do mundo, o rio Solimões/Amazonas e o rio Negro. Essa área apresenta dois ambientes bem distintos: a várzea e a terra firme. Isso propicia a existência de um diversificado ecossistema, com uma variada tipologia vegetal e pedológica. Também nessa área está concentrado um grande número de sítios arqueológicos das populações pré-colombianas que habitavam essa região (NEVES, 2003). O acesso à área de estudo é feito por via fluvial ou pela rodovia AM 070 sendo que, a partir de outubro de 2011, após a inauguração da ponte sobre o rio Negro, ligando Manaus a Iranduba, não foi mais preciso a travessia de balsa no trecho entre esses dois municípios. 


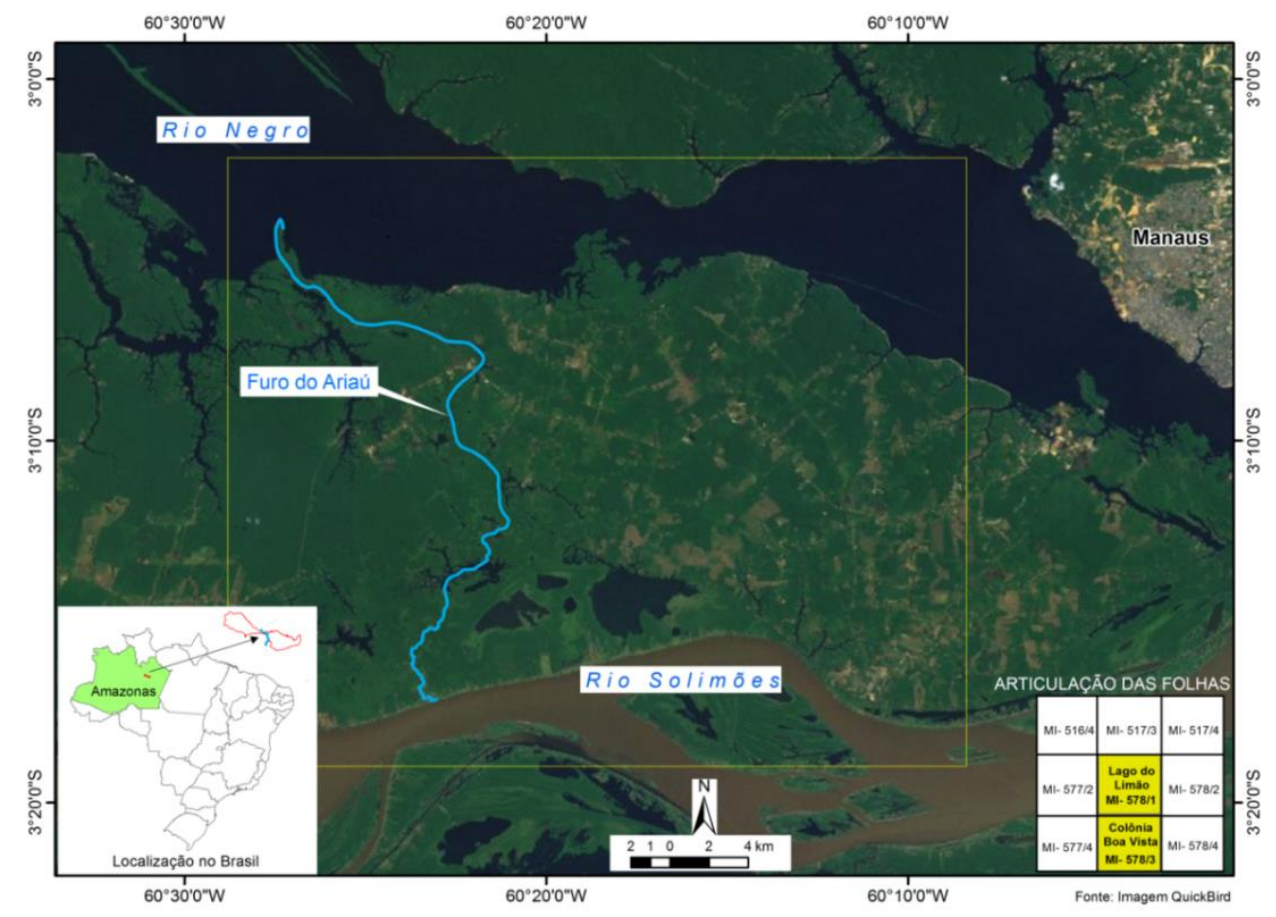

Figura 1 - Localização da área de estudo.

\section{MATERIAIS E MÉTODOS}

Os dados desta pesquisa são compostos de: imagens do sensor aerotransportado SAR R99B, adquirido no modo de mapeamento Quad L + X, com combinações polarimétricas na banda L (HH, HV, VH e VV) e uma na Banda X (HH), com resolução espacial de 6 metros. Essas imagens foram adquiridas em 15 de dezembro de 2005.

A base cartográfica empregada foram as seguintes: Carta Topográfica na escala de 1:50.000 Folhas SA-20-Z-D-III-1 Lago do Limão e SA-20-Z-D-III-3 Colônia Boa Vista, DSG, 1984, assim como os arquivos vetoriais digitais da base de dado do IBGE/SIPAM, contendo dados de drenagem, geologia, geomorfologia, vegetação e pedologia na escala de 1:250.000. A análise e o tratamento das imagens foram realizados com uso do software ENVI 4.7, ERDAS 9.1 e o acabamento, impressão e elaboração dos mapas no software ArcGis 10.

Os métodos e procedimentos adotados nesta pesquisa foram divididos nas seguintes fases: 1- Levantamento dos dados disponíveis e pré-processamento; 2- Processamento dos dados; 3- Análise e interpretação dos resultados.

$\mathrm{Na}$ fase 1 foram realizados os levantamentos bibliográfico, cartográfico e de sensoriamento remoto, bem como o primeiro levantamento de campo para reconhecimento da área de estudo. Nessa fase, foi realizado o pré-processamento das imagens SAR R99B, com a 
correção geométrica e correção do padrão da antena. Em seguida, realizou-se o corte e seleção da área de interesse nas imagens de radar e, por último, o mosaico das cenas e filtragem.

A segunda fase, a qual corresponde ao processamento dos dados, foram feitas as interpretações dos dados de sensoriamento remoto como subsídios para o mapeamento geomorfológico, através da chave de interpretação e, com o auxílio do trabalho de campo, pôde-se definir as principais formas do relevo na área de pesquisa. A análise dos dados de sensoriamento remoto, para interpretação da imagem de radar, foi adaptada do método de Lima (1995), composta de três fases: identificação dos elementos, análise e interpretação. Dessa forma, foi criada a chave de interpretação, possibilitando uma maior discrição das diversas formas encontradas na área de estudo (Figura 2).

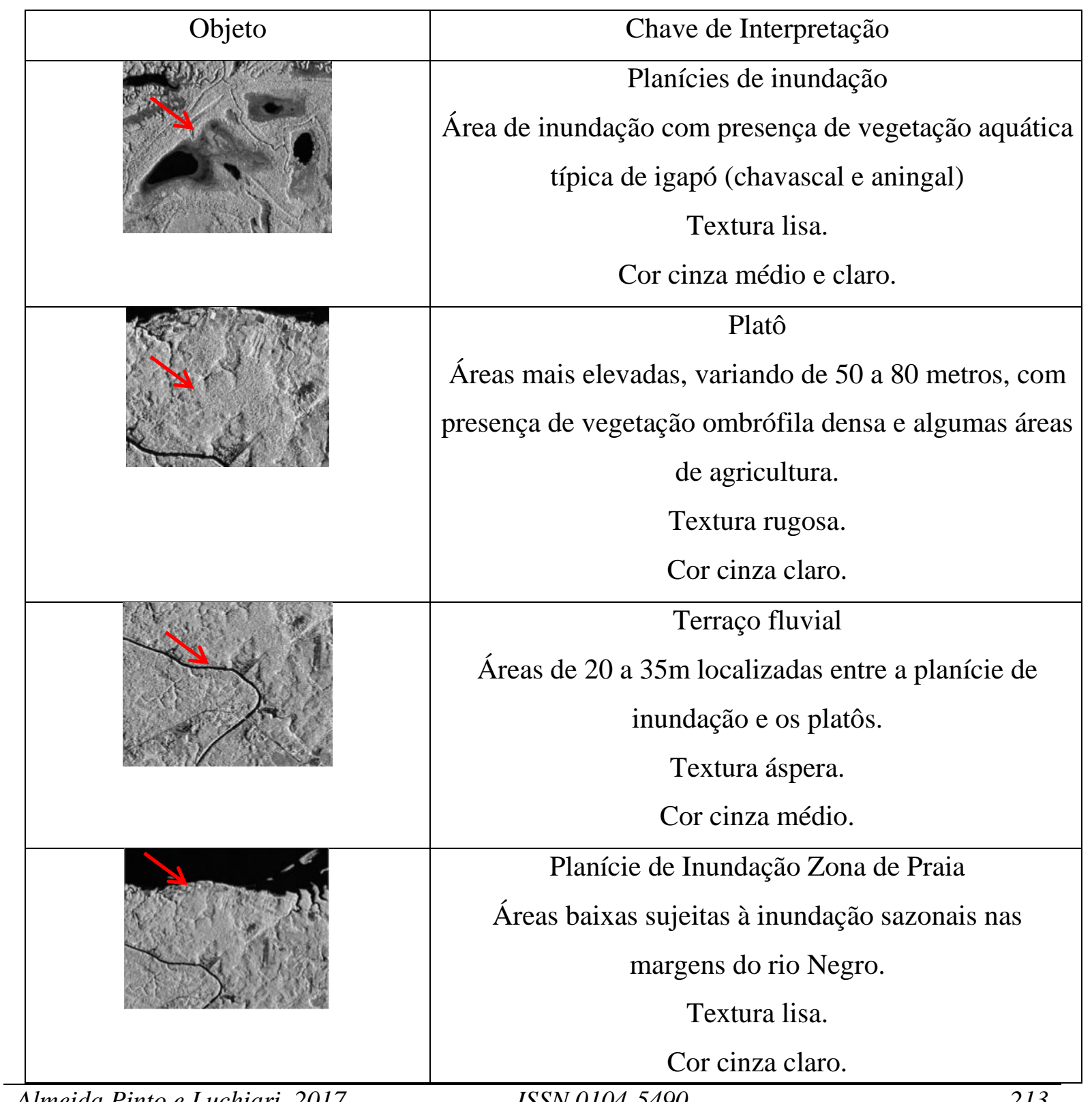




\begin{tabular}{|c|c|}
\hline & Rede de Drenagem \\
Área no fundo de vale & Textura média \\
Cor cinza escuro e médio \\
\hline
\end{tabular}

Figura 2- Chave de interpretação das diferentes formas de relevo e uso da área do Ariaú.

Na fase 3, correspondente à análise e interpretação dos resultados, foi feita, primeiramente, a extração da rede de drenagem, tendo como base as imagens do SAR R99 e usando como auxílio às cartas topográficas da DSG. O processo de vetorização foi realizado no software ArcGis 10. A análise da rede de drenagem foi feita conforme descrito em Lima (1995): grau de integração; densidade; tropia; grau de controle; sinuosidade; ângulo de junção e assimetria. A densidade da drenagem foi gerada através da função Kernel, descrita por Silverman (1988), utilizando o Software ArcGis 10. Foram definidos quatro grupos de densidade (baixa, média, alta e muito alta). Ainda foi realizado o levantamento da hierarquia fluvial, tendo como base os parâmetros estabelecidos por Strahler da ordem dos canais.

\section{RESULTADO E DISCUSSÕES}

\section{Extração da rede de drenagem vetorizada e análise dos dados}

Um dos elementos que contribuem para o entendimento da geomorfologia de uma determinada região é, sem dúvida alguma, a rede hidrográfica. Segundo Christofoletti (1980), as drenagens fluviais sempre tiveram uma importância relevante na geomorfologia pois, por meio da análise da rede hidrográfica podem levar à compreensão e a elucidação de várias questões geomorfológicas.

Nessa etapa foram vetorizados os corpos d'água da área de estudo, sendo que os rios de maior volume de água, paranás e os lagos aparecem com uma melhor definição nas Almeida Pinto e Luchiari, 2017

ISSN 0104-5490

214


imagens de radar, devido à reflexão especular das microondas na direção oposta da antena, não tendo, portanto, nenhum sinal registrado no sensor, aparecendo uma imagem com tons de cinza escuro (preto). Optou-se por não utilizar a polarização L VV para o mapeamento dos corpos d'água devido espalhamento muito forte nesta polarização, ocasionando dificuldade na interpretação.

O resultado da extração manual da rede de drenagem através das imagens do SAR possibilitou visualização dos cursos d'água de menor porte, onde a maioria desses cursos não é vista nas cartas topográficas e nem nas imagens dos sensores ópticos, isso porque o tipo de comprimento da onda interfere diretamente no sinal de retorno para o sistema radar (Figura $3)$.
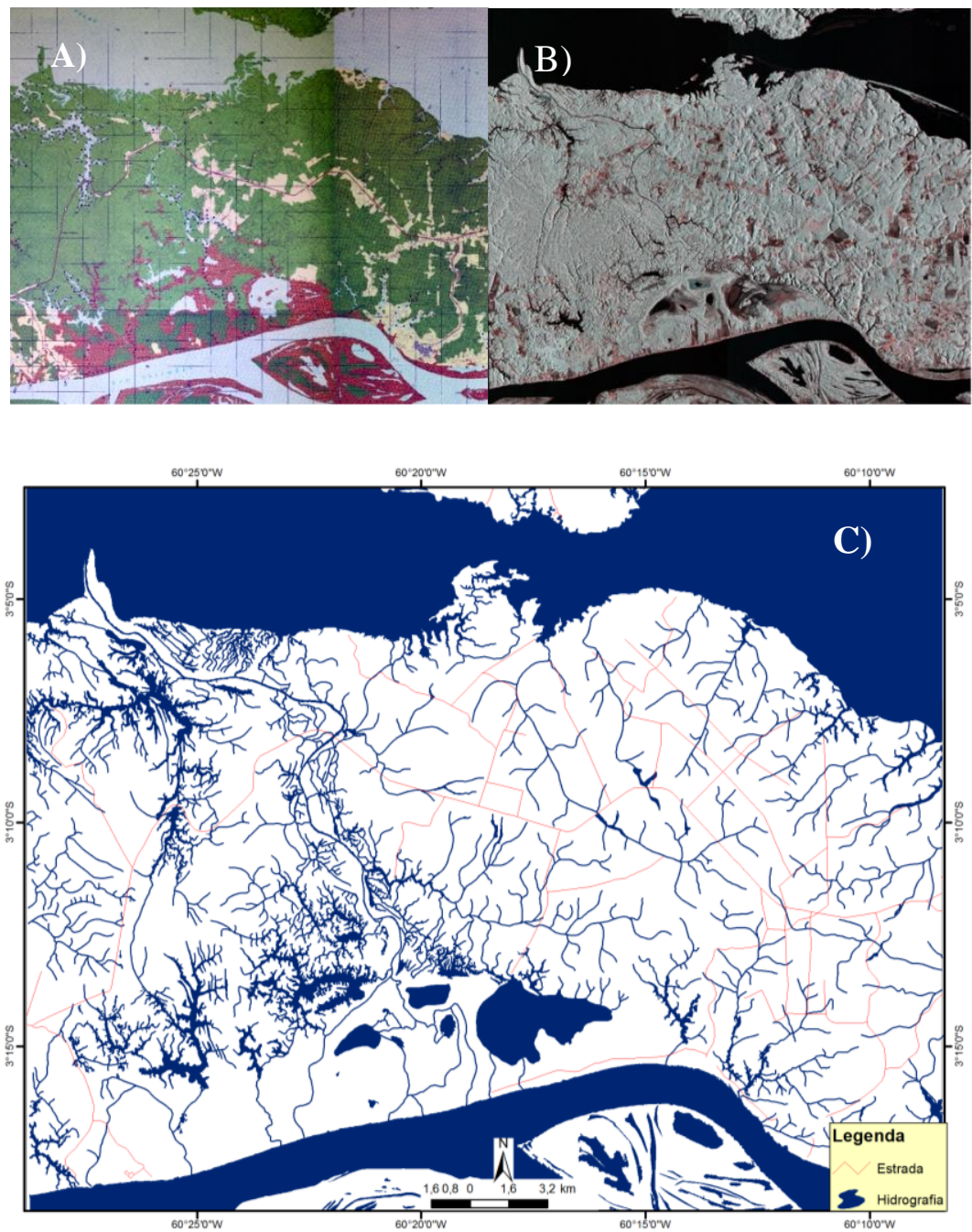

Figura 3- Hidrografia da área do Ariaú: em a) mosaico das cartas topográficas utilizadas como base; em b) mosaico da imagem SAR composição colorida falsa cor Rhh, Ghv e Bvh; em c) hidrografia vetorial gerada com base na interpretação do SAR. 
Segundo Lueder (1959 apud LIMA, 1995), os principais parâmetros a serem estudados nos padrões de drenagem são: grau de integração, densidade, tropia, grau de controle, sinuosidade, ângulo de junção e assimetria.

Em relação ao grau de integração, a drenagem é mais alta na parte NE e SE, com traçado visível na área próxima ao lago do Ubim. Por ser uma região com relevo mais baixo e com a vegetação mais densa, o grau de integração da drenagem é de médio a baixo.

A densidade de drenagem varia, em geral, de muito baixa a muito alta, de acordo com a quantidade de drenagens e comprimento dos vetores por unidade de área $\left(\mathrm{km}^{2}\right)$. Os resultados alcançados com a densidade de drenagem extraída da área de estudo, demonstram que a rede de drenagem é mais densa próximo do furo do Ariaú e ao longo dos lagos, na região NW da área de pesquisa. Em contrapartida, na parte NE e SE da área de estudo, a densidade varia de média a baixa. Esse resultado evidencia um tipo diferenciado de solo e mesmo de relevo, pois nas áreas de alta densidade o solo pode ser extremamente impermeável (Figura 4).

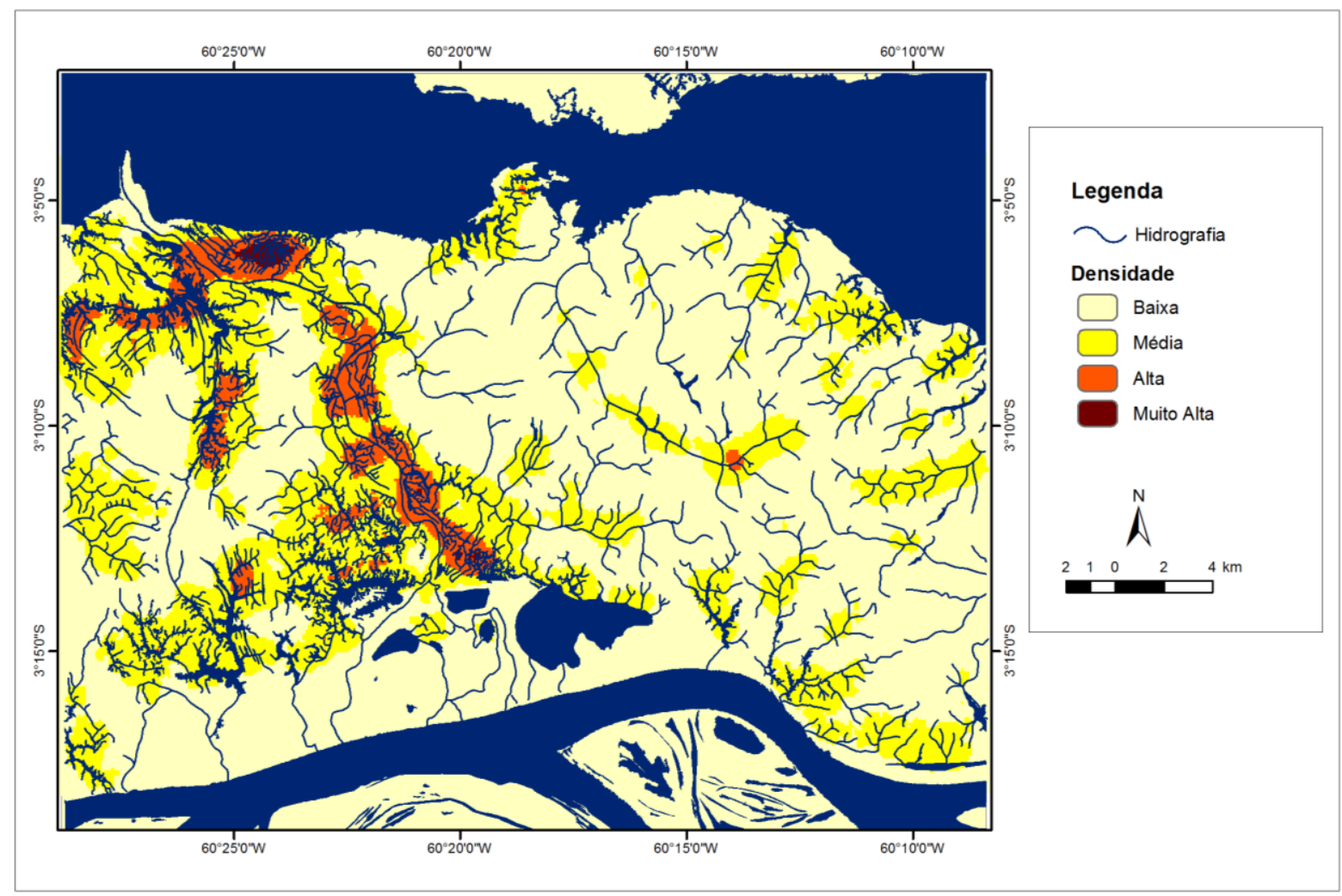

Figura 4- Mapa da Densidade de drenagem obtido a partir do mapa drenagem final $\mathrm{em} \mathrm{km} / \mathrm{km}^{2}$. 
Em relação à tropia do sistema de drenagem da área de estudo, pode-se classificá-la como unidirecional em relação aos grandes sistemas, rio Negro e Solimões, multidirecional nos pequenos cursos e tropia desordenada nos cursos que interligam com o furo do Ariaú. Com o resultado da tropia da rede de drenagem, podemos inferir que o grau de controle dos grandes caudais é forte e dos pequenos cursos o controle é fraco.

Em relação à sinuosidade e a angulosidade do sistema de drenagem da área, pela análise da rede, podemos caracterizar que não foi encontrada nem um curso que fuja ao padrão normal, com exceção do rio Negro, que apresenta uma modificação no seu padrão de drenagem de anastomosado para retilíneo e mudança brusca de direção próxima a área do Jacareubal. Já em relação à assimetria, a drenagem da área é bem fraca. Porém, a drenagem do lago do Limão apresenta uma assimetria de média à forte, onde os afluentes da margem direita são maiores que os da esquerda.

Segundo Silva (2005), o sistema de drenagem na área do Ariaú é fracamente desenvolvido, pois situa-se em uma superfície rebaixada. Porém, existe uma complexidade de formas e padrões devido aos diferentes tipos de depósitos fluviais (terraços, barras de migração e recente do furo do Ariaú), que formam canais afogados com padrão retangular.

Em relação aos padrões de drenagem reconhecidos na área de estudo, podem ser classificados como dendrítico, sub-dendrítico e complexo. Em relação à rede dendrítica, podemos citar os seguintes igarapés: do Testa; do Chico Preto e o da Montanha Russa, todos na parte nordeste da área de estudo. Já o sistema sub-dendrítico, na área, é o igarapé da Cachoeira, na parte central. O padrão de drenagem tido como complexo, é encontrado relacionado diretamente ao curso do furo do Ariaú, onde se verifica um emaranhado de canais que se interligam e que têm contato direto com o curso principal do Ariaú. Em relação à hierarquia fluvial, foram encontrados padrões de canal até a quarta ordem, conforme a classificação de Strahler.

\section{Mapeamento geomorfológico das principais feições fluviais.}

A área de estudo encontra-se inserida nas unidades geomorfológicas da Planície Amazônica e do Planalto Dissecado Rio Trombetas-Rio Negro (RADAMBRASIL, 1978). O domínio da Planície Amazônica é caracterizado por planícies de inundação e terraços fluviais muito amplos. O Planalto Dissecado Rio Trombetas-Rio Negro, também denominado de Baixos Platôs da Amazônia Oriental, está representado por colinas pequenas e médias 
dissecadas, vales fechados e drenagens dendríticas e subdendríticas (SILVA, 2005; DANTAS \& MAIA, 2010). Na área de estudo foram identificadas as seguintes unidades morfológicas: 1- Platô, 2-Planície Fluvial e 3-Terraço Fluvial (Figura 5).

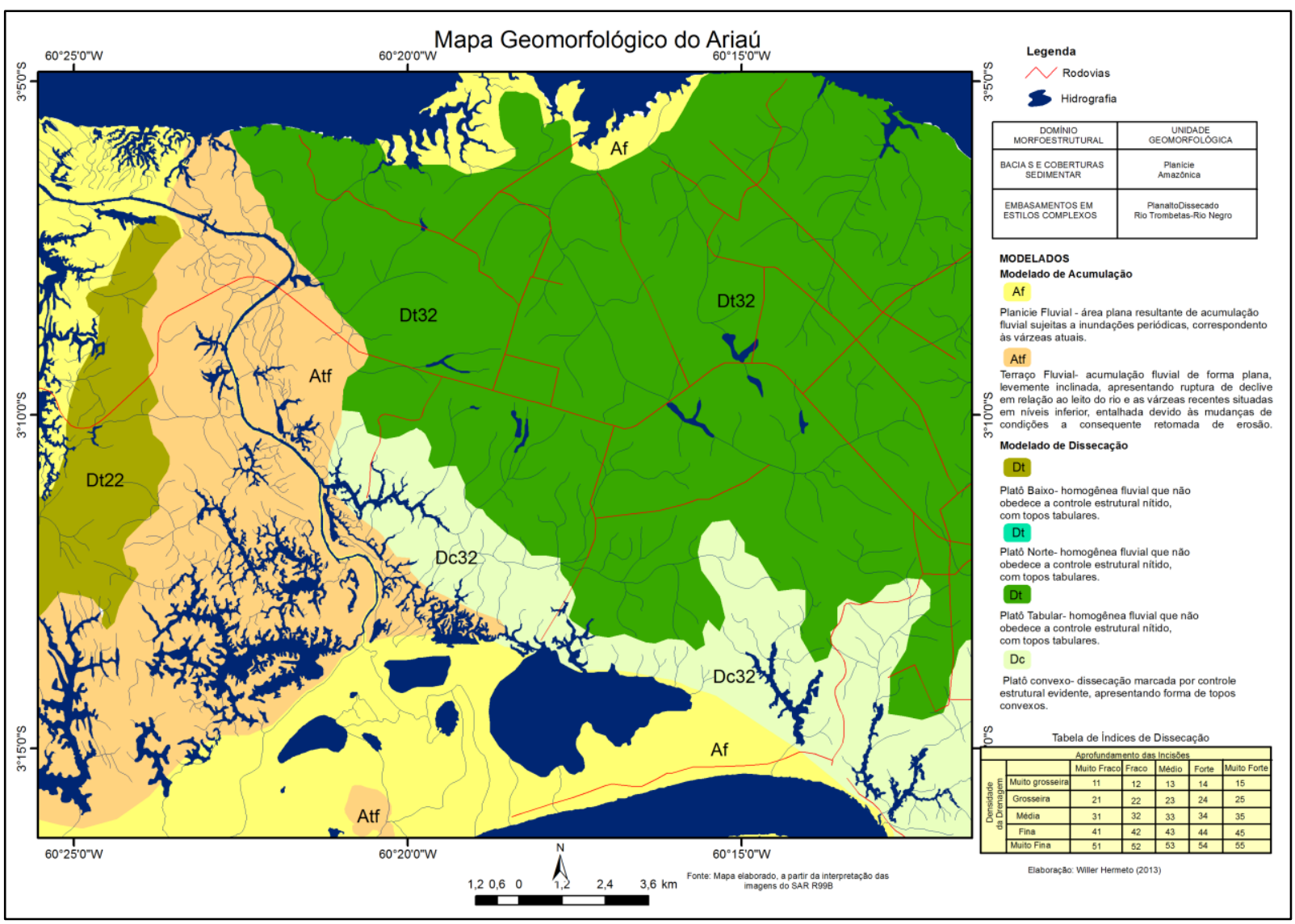

Figura 5 - Mapa geomorfológico da área do Ariaú.

1- Platô- Pela interpretação das imagens SAR R99B pode-se dividir em três subunidades correspondentes à área do Ariaú: os de topos tabulares, os de topos convexos e o baixo-platô.

As subunidades dos platôs de topos tabulares estão situadas na parte central e nordeste da área de estudo. Essa subunidade é a que contém as cotas mais elevadas da área de pesquisa, variando de 80 a 100 m, inserida na formação Alter do Chão e representada, normalmente, por rochas sedimentares intemperizadas e laterizadas. O solo predominante nesta subunidade é o Latossolo Amarelo. No entanto, o Espodossolo aparece no fundo de alguns vales, geralmente encontrado em pequenas manchas nas proximidades de igarapés e, embora menos comum, no terço médio de algumas vertentes, essa classe de solo não aparece no mapa de solos devido a sua pequena extensão, bem como as manchas de solo de Terra Preta bastante 
comuns na área de pesquisa. Tanto o Espodossolo quanto a Terra Preta, são cobertos por uma vegetação típica de campinas e campinaranas (SOARES, 2007). Segundo o IBGE (2002), a vegetação predominante nesses platôs é de Floresta Ombrófila Densa de Terras Baixas. No entanto, devido à ação antrópica intensa nessa área, grande parte da vegetação original já foi retirada para o uso e ocupação do solo para agricultura. Nas imagens SAR R99B, essa unidade aparece com uma textura grossa com tons de cinza claro e médio (Figura 6).

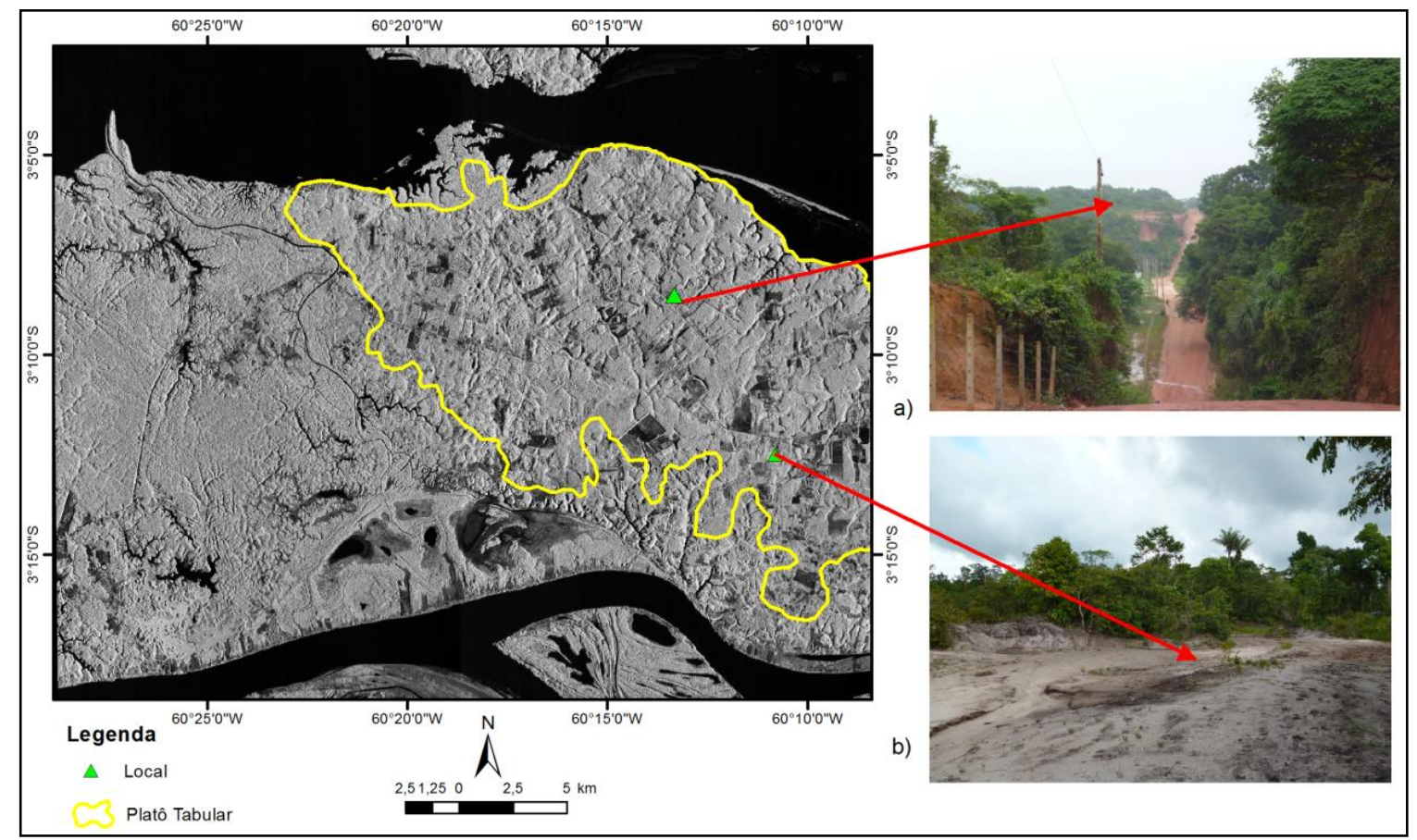

Figura 6- Mosaico da imagem SAR Banda Lvv da área de estudo. a) Platô de topo tabular na parte nordeste da área; b) área com Espodossolo e vegetação de campinara, sitío arqueológico Dona Stella.

Platôs de topos convexos estão situados na parte sul-sudeste da área de estudo, e são uma área de contato com a planície fluvial do rio Solimões/Amazonas. A drenagem é do tipo dendrítica, apresentando igarapés com vales afogados. O solo é do tipo Latossolo Amarelo com vegetação de Floresta Ombrófila Densa de Terras Baixas. Também apresenta vegetação secundária, capoeira, além de apresentar uma intensa modificação na paisagem pelo uso e ocupação do solo. É nessa área que se encontra a sede do município de Iranduba. Segundo Maia (2007), nessa área reúne formas de relevo caracterizadas por superfícies colinosas de topo convexo tabular, separada por vales de declive moderado. Essa subunidade aparece com uma textura muito grossa na imagem de radar do R99B, com tons de cinza variando de claro a médio. 
Baixo-platô- essa subunidade apresenta nível abaixo de 50 metros e está na parte oeste da área de estudo, em contato com os terraços fluviais e com a planície de inundação. Apresenta vegetação de Floresta Ombrófila Densa das Terras Baixas com Dossel Emergente (IBGE, 2002). Segundo Maia (2007), essa unidade caracteriza-se por apresentar uma superfície plana levemente ondulada, com entalhamento dos vales muito fraco ( $<20$ metros) e com um relevo de amplitude inferior a 50 metros, sendo a rede de drenagem influenciada, principalmente pelo Lago do Ubim. Conforme Silva (2005), nessa área ocorrem depósitos argilosos e siltosos com níveis arenosos intercalados, de coloração cinza. Esses depósitos são bastante utilizados pela indústria oleira para fabricação de telhas de barro e tijolos. Nos trabalhos de Silva (2005) e Soares (2007), esses depósitos estão sendo considerados como pertencente ao Quaternário, diferente do mapeamento geológico realizado pelo RADAMBRASIL, que considerou essa área como sendo da Formação Solimões. No mapa geológico do IBGE (2002) está configurado como pertencente à Formação Içá. O baixo platô aparece com uma textura fina na imagem de radar e com tons de cinza claro.

2- Planície Fluvial- essa subunidade foi dividida em duas: Planície Fluvial do rio Negro e Planície Fluvial do rio Solimões/Amazonas. De acordo com Barbosa et al. (1978), pelo fato do rio Solimões/Amazonas ter sua nascente na cordilheira dos Andes e drenar uma área composta de sedimentos tenros e recentes, tem um potencial de deposição bastante elevado na sua planície fluvial. Por outro lado, o rio Negro, que tem suas nascentes no Complexo Guianense, região bastante erodida, utiliza sua potência nos processos de encaixamento do seu leito. Por isso, a diferenciação no tocante à construção de suas planícies pois, enquanto o Solimões/Amazonas carrega uma carga de sedimentos alta, o rio Negro, ao contrário, transporta pouco material em suspensão.

A planície fluvial do rio Negro é pobre em nutrientes. Isso devido à elevada acidez de suas águas de coloração escura, com variação de pH entre 3,8 a 4,9, apresentando uma grande quantidade de substâncias orgânicas dissolvidas, provenientes de solos arenosos cobertos por vegetação de campinarana (CARNEIRO, 1995; TEIXEIRA et al., 2009). Essa subunidade situa-se na confluência do furo do Ariaú com o rio Negro, juntamente com o lago do Ubim na parte noroeste da área de estudo, e ainda, na região do Jacareubal na porção norte. É nessa subunidade que, durante o período de vazante e de seca do rio Negro encontramos zonas de praia. Segundo Albuquerque et al. (2012), a composição mineralógica é definida por sedimentos formados no Quaternário, cuja composição é predominantemente de areia 
quartzosa. Na imagem do SAR R99B essa subunidade aparece com uma textura lisa e tons de cinza claro.

A Planície Fluvial do rio Solimões/Amazonas é denominada localmente de várzea. Esse rio carrega uma elevada carga de sedimentos em suspensão e, associados ao nível elevado do lençol freático e às inundações periódicas, condicionam um processo incipiente de pedogênese (IRION, 1984). Essas áreas denominadas várzeas, estão sujeitas a inundações sazonais, compondo uma planície aluvial que pode alcançar uma grande extensão, com um sistema complexo de canais, lagos, ilhas e diques marginais (SIOLI, 1951).

Essa subunidade está localizada em toda a parte sul da área de estudo e apresenta os seguintes tipos de formação vegetal: Floresta Ombrófila Densa Aluvial com Dossel Emergente, Formação Pioneira Herbácea sem Palmeira e áreas de cultura cíclicas (IBGE, 2002). Nessa área predominam os solos aluviais (Gleissolos e os Neossolos Flúvicos), devido à dinâmica fluvial muito intensa: cheia, enchente, vazante e seca. A paisagem é bastante transformada, surgimento de inúmeras ilhas, diques marginais e cordões arenosos alongados no interior do canal. De acordo com Teixeira et al. (2007), os solos de várzea têm elevada fertilidade natural e desempenham um papel de suma importância na produção agrícola da região, pois são intensamente utilizados pelos pequenos agricultores ribeirinhos da região. Para Neves (2005), os pequenos agricultores ribeirinhos se configuram mais como policultores (agricultores, pescadores e extratores de recursos florestais), sendo que a maioria se dedica a cultivos de ciclo curto, isso devido ao efeito da alagação do grande rio . Essa subunidade também aparece com textura lisa na imagem do SAR R99B.

3-Terraço Fluvial- essa subunidade está localizada principalmente nas margens do furo do Ariaú. No entanto, também verifica-se a ocorrência de pequenos terraços na margem do Solimões/Amazonas, na parte sul da área de estudo. Os terraços mais recentes, holocênicos, são representados, principalmente, por depósitos de acresção lateral e de transbordamento, sujeitos à dinâmica atual dos rios. A densidade da drenagem, neste local, é de muito alta a alta nos terraços nas margens do furo do Ariaú. Segundo Maia (2007), de maneira geral os terraços são superfícies planas e levemente inclinadas e pouco dissecadas nessa área e grande parte caracterizadas com argila. De acordo com Silva (2005), no terraço do furo do Ariaú ocorrem sedimentos quaternários, material essencialmente argiloso, onde essas argilas já são localmente exploradas e constituem a fonte de matéria-prima para a indústria oleira de Iranduba (MAIA, 2007). Nas imagens do SAR essa subunidade aparece com uma textura média com tons de cinza claro. 


\section{Mapeamento das feições fluviais}

As feições fluviais definidas para o mapeamento foram: igarapés, furos, lagos, rios, ilhas fluviais e barras de sedimentos (Figura 7).

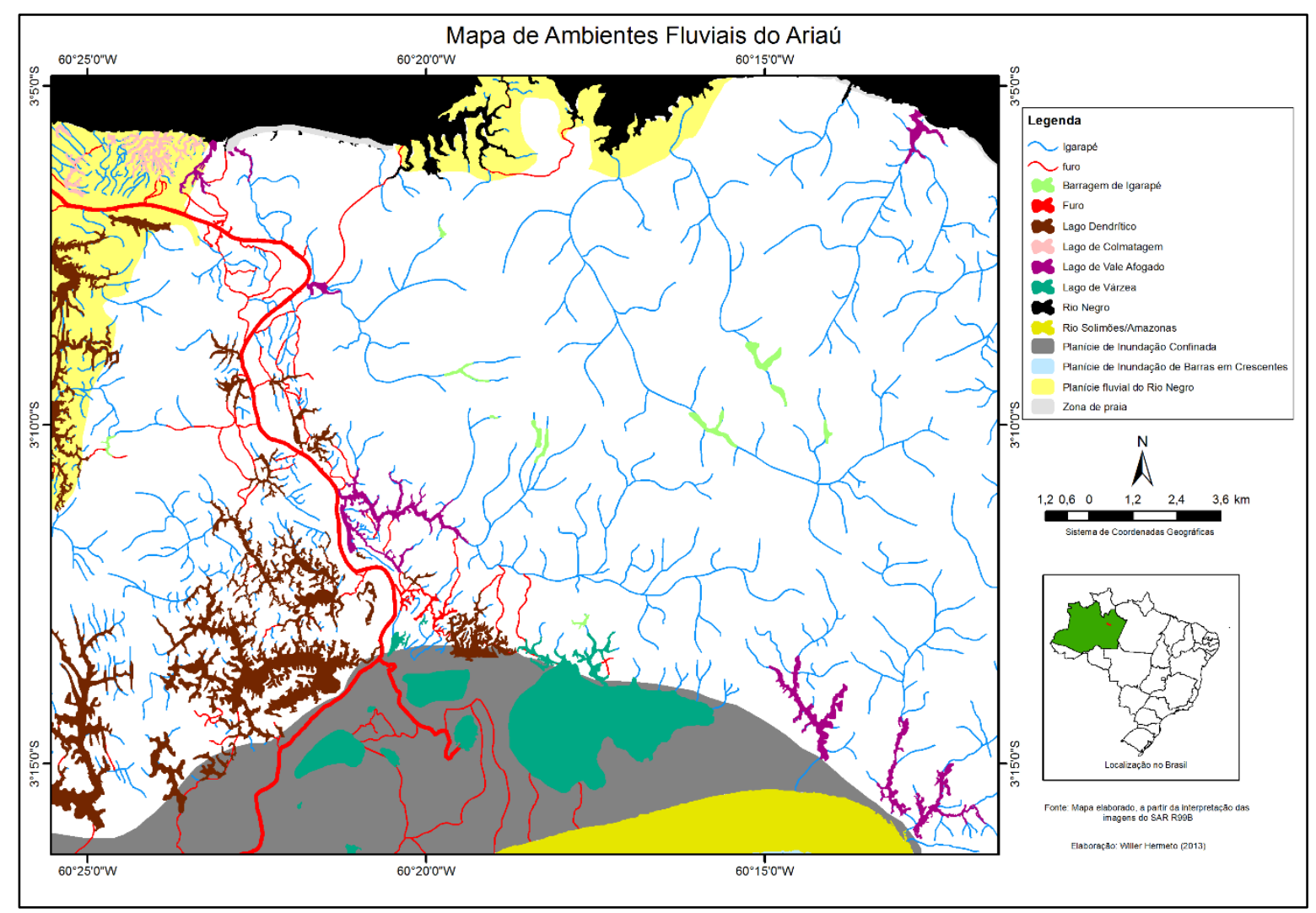

Figura 7 - Mapa de Ambientes Fluviais da área do Ariaú.

Os igarapés se configuram em toda a área da pesquisa e são os ambientes predominantes em toda a região, sobrelevam os cursos de primeira e segunda ordem, conforme a classificação de Strahler. Os igarapés, nessa área, são feições com bacias bem definidas de pouca extensão e de largura reduzida (SOARES, 1997). A feição dos furos predomina na parte oeste da área de pesquisa em toda a extensão do canal principal do furo do Ariaú, sendo que, na parte leste, não foi encontrada nenhuma dessa feição fluvial.

Em relação às feições lagos, foram mapeadas as seguintes tipologias: lago dendrítico, lago de restinga, lago de vale afogado e lago de várzea. Os caracterizados como sendo lagos dendríticos estão concentrados na parte oeste da área de estudos. Esse tipo de lago é bastante 
ramificado, sendo que o de maior extensão na área de pesquisa é o lago do Ubim na região noroeste. Uma rede complexa de igarapés e furos faz ligações com esses tipos de lagos (Figura 8).

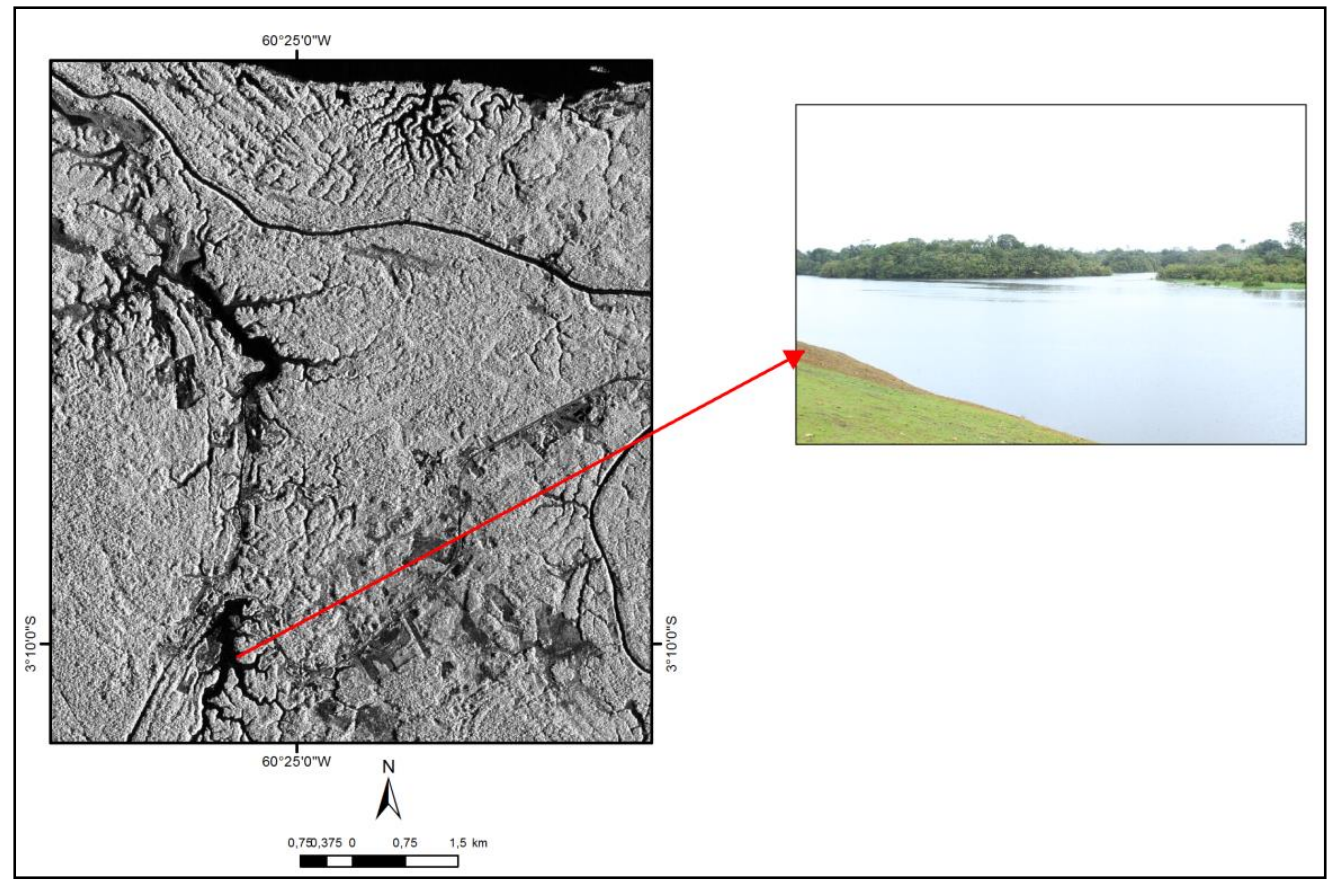

Figura 8- Lago dendrítico do Ubim na parte oeste do município de Iranduba

Os lagos de restingas denominados por Nascimento et al. (1976), são os que se encontram na margem do rio Negro, na região noroeste da área de estudo. No entanto, apesar da denominação lago de restinga, esses lagos ainda têm contato direto com os rios. Apesar do processo de colmatagem, que gerou vários furos e canais de ligação direta, pode-se aventar que o processo de colmatagem que vem ocorrendo nessa área tem sido originado pelos sedimentos vindo do furo do Ariaú.

Os lagos de vales afogados, também chamados de rias fluviais (BARBOSA et al., 1978) ou mesmo de rias de água doce (GUERRA, 1962), estão representados na parte nordeste, sul e central da área de pesquisa. Na parte nordeste e central os lagos não apresentam o que Sternberg (1950) chamou de dilatação lacustre, ocasionada na boca dos vales provocada pelos sedimentos depositados ocasionando joelho de fratura. Há de se destacar que na parte central, o único lago encontrado com essa feição de vale afogado foi o lago do Limão. Esse lago, também no período da cheia, tem contato com o rio Solimões/Amazonas por meio do lago Grande (NEVES, 2000). Os de vales afogados, que se 
concentram na da parte sul, são mais retilíneos e neles se verifica a presença da colmatação de sedimentos, ocasionando um barramento do canal.

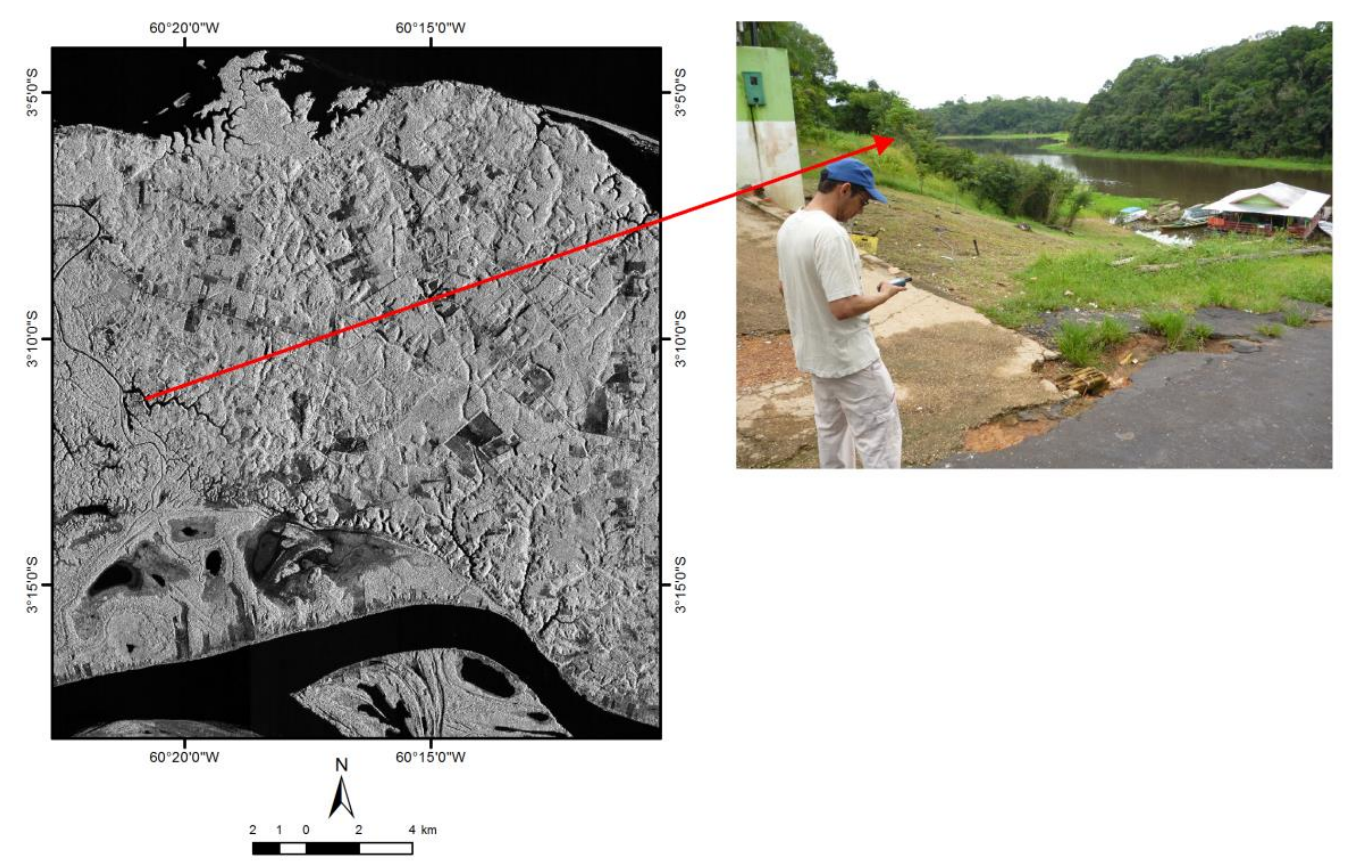

Figura 9 - Recorte na imagem da área e em destaque o Lago do Limão que apresenta vale afogado.

Os lagos de várzea são os mais presentes na área de estudo e estão concentrados todos na parte sul. Esses tipos de lagos estão diretamente, ou parcialmente, relacionados com a dinâmica fluvial do rio Solimões/Amazonas: ora são alimentados pelo transbordamento do rio principal; ora através dos canais de ligação (furos). Segundo Ayres (1995), esses tipos de lagos são bastante cobertos por vegetação arbustiva, pantanosa e são quase intransponíveis no período da seca.

Em relação ao mapeamento dos rios na área de pesquisa, isto é, os dois caudais, rio Negro e Solimões/Amazonas já foi bastante discutido ao longo deste trabalho. Desta forma, só apresentaremos as outras feições a eles que integram a geomorfologia fluvial.

As feições de ilhas são encontradas tanto no canal do rio Negro quanto no do Solimões/Amazonas. Porém, as ilhas do rio Negro em menor proporção, sendo que algumas só aparecem no período da seca na região. Quanto às do Solimões/Amazonas, devido à dinâmica maior do rio e de sua velocidade, as ilhas nesse canal estão em processo muito grande de colmatação e apresentam, geralmente, lagos em seu interior. Segundo Latrubesse 
(2002), essas ilhas são planícies de inundação caracterizadas por barras em crescente. Essas barras são truncadas pelo canal principal do rio como pelo seu braço lateral (paraná).

\section{CONCLUSÕES}

De acordo com os objetivos propostos nesta pesquisa de identificação das formas de relevo existentes na área do furo do Ariaú, utilizando as imagens do SAR/R99B para o mapeamento geomorfológico. A metodologia aplicada na área de estudo, permitiu individualizar as diferentes feições do relevo nas terras baixas no município de Iranduba por meio da chave de interpretação das informações extraídas dessas imagens.

Os resultados demonstraram o potencial do emprego das imagens do sistema de radar imageador SAR/R99B como uma eficaz ferramenta para o mapeamento geomorfológico, em áreas de relevo pouco dissecado e de baixa amplitude altimétrica, principalmente, na diferenciação das feições fluviais. Desta forma, foi possível identificar os modelados de acumulação, planícies e terraços fluviais, bem como os modelados de dissecação, os diferentes tipos de platôs na área do Ariaú.

Notamos que com a utilização da composição colorida das polarizações foi possível diferenciar, com maior precisão e detalhe os tipos de canais fluviais, quanto a sua forma e tipologia e, com isso, extrair a rede de drenagem da área de estudo. Pode-se desta forma, obter os diferentes padrões de drenagem da área de pesquisa, bem como a densidade da rede de drenagem.

Apesar das imagens do SAR R99B já tenham coberto mais de 60\% da Amazônia Legal, tenha uma boa qualidade radiométrica, uma excelente resolução espacial, com áreas imageadas desde 2004 e pelo fato dessas cenas estarem disponíveis de forma gratuita, no entanto, poucos estudos têm sido evidenciados em relação ao mapeamento geomorfológicos, ficando evidente uma lacuna a ser preenchida.

Desta forma, pode-se concluir que a metodologia para o mapeamento das feições geomorfológicas fluviais empregadas nessa pesquisa demostra um potencial da utilização do SAR/R99B para esse fim. O que fica evidente a utilização dessas imagens para o uso no mapeamento dos ambientes fluviais e geomorfológicos das terras baixas da Amazônia. 


\section{REFERÊNCIAS}

ALBUQUERQUE, A. R. C. ; ALBUQUERQUE, C. ; RODRIGUES, E. G. . FEIÇÕES DE RELEVO DA MARGEM DIREITA DO RIO NEGRO: MUNICÍPIO DE IRANDUBA (AM). In: IX Simpósio Nacional de Geomorfologia, 2012, Rio de Janeiro. Anais do IX Simpósio Nacional de Geomorfologia, 2012.

ALMEIDA FILHO, R.; MIRANDA, F.P. Mega capture of the Rio Negro and formation of the Anavilhanas Archipelago, Central Amazônia, Brazil: Evidences in an SRTM digital elevation model. Remote Sensing of Environment, v.110, 2007, p.387- 392.

AYRES, J.M.C. As matas de várzea do Mamirauá. Brasília, DF: CNPq; Tefé, AM: Sociedade Civil Mamirauá, Brasil. 1995.

BARBOSA G.V. COSTA, R.C.R., NATALI T. FILHO, OLIVEIRA A.B. 1978. In: BRASIL. Projeto RADAM. Geomorfologia da Folha SA.20-Manaus. DNPM, Geomorfologia, Levantamento de Recursos Naturais, Rio de Janeiro, 167-224.

CARNEIRO, A. E. V. Análise quantitativa do sedimento depositado nas planícies de inundação do rio Solimões/Amazonas, utilizando a técnica de fluorescência de raios $\mathbf{X}$ por dispersão de energia. São Paulo, 1995. 232p. Tese (Doutorado) - Instituto de Pesquisas Energéticas e Nucleares.

CHRISTOFOLETTI. Geomorfologia. $2^{\circ}$ Ed. São Paulo: Editora Edgard Blucher, 1980.

CUNHA, C. L. M.; MENDES, I.A; SANCHEZ, M.C. A Cartografia do Relevo: Uma analise comparativa de técnicas para a Gestão Ambiental. Revista Brasileira de Geomorfologia. 2003. 4: 1-9.

DANTAS, Marcelo Eduardo ; MAIA, Maria Adelaide Mansini . Compartimentação Geomorfológica. In: Maria Adelaide Mansini Maia; José Luiz Marmos. (Org.). Geodiversidade do Estado do Amazonas. Manaus: CPRM, 2010.

FLORENZANO, T. G. Geomorfologia: conceitos e tecnologias atuais. São Paulo: Oficina de Textos, 2008.

GUERRA, A. T. Vales submersos na Amazônia. Revista Brasileira de Geografia: Sumário do número de julho-setembro de 1962.

HESS, L.L; MELACK, J.M.; NOVO, E.M.L.M; BARBOSA, C.C.F.; GASTIL, M. DualSeason Mapping of Wetland Inundation and Vegetation for the Central Amazon Basin. Remote Sensing of Environment, 2003, 87: 404428.

HORBE A.M.C., PAIVA M.R.P.d., MOTTA M.B., HORBE M.A. Mineralogia e geoquímica dos perfis sobre sedimentos neógenos e quaternários da bacia do Solimões na região de Coari - AM. Acta Amazônica 37:81, 2007. 
INSTITUTO BRASILEIRO DE GEOGRAFIA E ESTATÍSTICA- IBGE. Mapa Geomorfológico Folha Manaus - SA 20Z-D, escala 1 :250.000 Diretoria de Geociência, 2002 .

IRION, G. Clay minerals of Amazonian soils, in: H. Sioli (Ed.), The Amazon: limnology and landscape ecology of a mighty tropical river and its basin, W. Junk Publishers, Dordrecht. 1984, pp. 537-579

JENSEN, J.R. (1949). Sensoriamento remoto do ambiente: uma perspectiva em recursos terrestres. EPIPHANIO, J.C.N.; FORMAGGIO, A.R; SANTOS, A.R.; RUDORFF, B.F.T.; ALMEIDA, C.M.; GALVÃO, L.S. (Tradução). São José dos Campos: Parêntese. 2009.

JUNK, W. J. General Aspects of Floodplain Ecology with Special Reference to Amazonian Floodplain, 3-20. In: The Central Amazon Floodplain, Ecology Of A Pulsing System. Junk, W. J. (Ed.) Ecological Studies 126, Springer. 1997

LATRUBESSE E.M. \& FRANZINELLI E. The Holocene alluvial plain of the middle Amazon River, Brazil. Geomorphology, 2002, 44:241-257.

LATRUBESSE, E. Perspectivas Hidrogeomorfológicas da Diversidade das Várzeas Amazônicas. In: Workshop de Geotecnologias Aplicadas às Áreas de Várzea da Amazônia. Manaus, 2007. p. 37-41.

LIMA, M. I. C. Introdução à interpretação radargeológica. Rio de Janeiro: IBGE, 1995. Série de Manuais Técnicos em Geociências, n.3, 124p.

MAIA, Maria Adelaide Mansini. Projeto materiais de construção na área Manacapuru Iranduba - Manaus - Careiro: domínio Baixo Solimões. CPRM - Serviço Geológico do Brasil, 2007.

MELACK JM, HESS LL .Remote sensing of the distribution and extent of wetlands in the Amazon basin. In: JUNK, W.J.; PIEDADE, M. (eds) Amazonian floodplain forests: ecophysiology, ecology, biodiversity and sustainable management. Ecological Studies, vol. 210, part 1. 2010, Springer, pp 43-59

NASCIMENTO, D.A. do; MAURO, C.A., de; GARCIA, M. das G.L. Geomorfologia In: BRASIL Departamento Nacional da Produção Mineral. Projeto RADAMBRASIL. Folha AS.21 Santarém. Rio de Janeiro, 1976. 522p. (Levantamento de Recursos Naturais, 10).

NEVES, E. G. Levantamento arqueológico área de confluência dos rios Negro e Solimões, estado do Amazonas. USP/FAPESP. 2000.

NEVES, E. G. Programa de Levantamento e Salvamento Arqueológico no Âmbito do Gasoduto Coari-Manaus. 2003.

NOVO, E.M.L.; FEREIRA, L.; BARBOSA, C.; CARVALHO, C.; SANO, E.; SHIMABUKURO, Y.; HUETE, A; POTTER, C.; ROBERTS, D.; HESS, L.; MELACK, J.; YOSHIOKA, H.; KLOOSTER, S.; KUMAR, V.; MYNENI, R.; RATANA, P.; DIDAN, K.; MIURA, T. Técnicas avançadas de sensoriamento remoto aplicadas ao estudo de mudanças 
climáticas e ao funcionamento dos ecossistemas amazônicos. Acta Amaz. [online]. 2005, vol.35, n.2, pp. 259-272. ISSN 0044-5967. Disponível em: <http://dx.doi.org/10.1590/S0044$59672005000200016>$.

PARADELLA, W. R.; SANTOS, A. R.; VENEZIANI, P.; CUNHA, E. S. P. Radares imageadores nas geociências: status e perspectivas. In: SIMPÓSIO BRASILEIRO DE SENSORIAMENTO REMOTO, 12. (SBSR), 2005, Goiânia. Anais... São José dos Campos: INPE, 2005. p. 1847-1854.

RADAMBRASIL. Folha SA. 20 Manaus: geologia, geomorfologia, solos, vegetação e uso pontencial da terra. Rio de Janeiro: DNPM, 628p (Levantamentos de recursos naturais, 18). 1978.

SILVA, C.L. "Análise da tectônica cenozóica na região de Manaus e adjacências". Rio Claro. Tese de doutorado em geologia regional, defendida no Instituto de Geociências e Ciências Exatas da Universidade Estadual Paulista (Unesp). 2005.

SILVERMAN, B.W. Density Estimation for Statistics and Data Analysis. Journal of the American Statistical Association, v. 83, n. 401, p. 269-270, 1988.

SIOLI, H. The Amazon And Its Main Afluentes: Hidrography, Morphology of the River Course, And River Types, 127-165. In: The Amazon, Limnology And Landcape Ecology Of A Mighty Tropical River And Its Basin. Sioli H. (Ed.) Junk Publ., Dordrecht. 1984.

SIOLI, H. Alguns resultados e problemas da liminologia amazônica. Belém, IPEAN, 1951. p.3-44 (IPEAN. Boletim Técnico, 24).

SOUZA FILHO, P. W. L. ; PARADELLA, W. R. ; SOUZA Jr., C.; VALERIANO, D. M. ; MIRANDA, F. P. . Sensoriamento Remoto e Recursos Naturais da Amazônia. Ciência e Cultura (SBPC), v. 3, p. 37-41, 2006.

SOARES, E.A.A. Depósitos pleistocenos da região de confluência dos rios Negro e Solimões, Amazonas. Tese (Doutorado) - Instituto de Geociências, Universidade de São Paulo, São Paulo. 2007, 205p.

STERNBERG, H.O'R. Vales Tectônicos da planície Amazônica? Revista Brasileira de Geografia. 1950, Ano XII (4), 3- 26.

TEIXEIRA, C.V.; SANO, E. E. . Utilização de Imagens Ópticas e de Rada pra Delimitação de Áreas e Identificação de Alvos Representativos na Várzea Amazônica: Proposta Metodológica. In: II Simpósio Brasileiro de Geomática e V Colóquio Brasileiro de Ciências Geodésicas, 2007, Presidente Prudente - SP. Anais do II Simpósio Brasileiro de Geomática e V Colóquio Brasileiro de Ciências Geodésicas, 2007. p. 1030-1033.

TEIXEIRA, W.G.; PINTO, W.H.; LIMA H.N.; MACEDO, R.S.; MARTINS, G.C.; ARRUDA, W.D.C. Os solos das várzeas próximas a calha do Rio Solimões - Amazonas no Estado do Amazonas, in: IBAMA (Ed.), Workshop Geotecnologias Aplicadas às Áreas de Várzea da Amazônia, Ibama, Manaus. 2007, p. 29 - 36. 
TEIXEIRA, W. G. ; PINTO, W. H. A. ; SILVA, C. B. S. ; LIMA, H. N. ; MACEDO, R. S. . O solo de várzea nas margens do rio Negro Amazonas - Brasil. In: XXXII Congresso Brasileiro de Ciência do Solo, 2009, Fortaleza. XXXII CBCS: O solo e a produção de bionergia: perspectivas e desafios. Fortaleza : Universidade Federal do Ceará, 2009. p. 494494 